\title{
Strain effects and electronic structures of narrow band P-R ferroelectrics: First principles calculation
}

\author{
Nedim Bozdag ${ }^{a}$, Husnu Koc ${ }^{a}$, Sevket Simsek ${ }^{b}$, Amirullah M. Mamedov ${ }^{c, d}$, and \\ Ekmel Ozbay ${ }^{c}$ \\ ${ }^{\mathrm{a} D e p a r t m e n t}$ of Physics, Faculty of Science and Letters, Siirt University, Siirt, Turkey; ${ }^{\mathrm{b}}$ Department of \\ Material Science and Engineering, Faculty of Engineering, Hakkari University, Hakkari, Turkey; \\ 'Nanotechnology Research Center, Bilkent University, Bilkent, Ankara, Turkey; ${ }^{d}$ International Scientific \\ Center, Baku State University, Baku, Azerbaijan
}

\begin{abstract}
In the present work, the structural, mechanical, electronic and optical properties of the Ruddlesden-Popper(RP) $\mathrm{Ba}_{3} \mathrm{X}_{2} \mathrm{~S}_{7}(\mathrm{X}=\mathrm{Zr}, \mathrm{Hf}, \mathrm{Ti})$ sulfides compounds have been investigated by means of first principles calculations. The generalized gradiend approximation has been used for modeling exchange-correlation effects. It has been observed that the calculated lattice parameters are in good agreement with the experimental values. Bulk modulus, shear modulus, Young's modulus Poisson's ratio, and Poisson's ratio from the calculated elastic constants for $\mathrm{Ba}_{3} \mathrm{Zr}_{2} \mathrm{~S}_{7}, \mathrm{Ba}_{3} \mathrm{Hf}_{2} \mathrm{~S}_{7}$, and $\mathrm{Ba}_{3} \mathrm{Ti}_{2} \mathrm{~S}_{7}$ compounds, respectively have been obtained. The obtained electronic band structure for $\mathrm{Ba}_{3} \mathrm{Zr}_{2} \mathrm{~S}_{7}$ and $\mathrm{Ba}_{3} \mathrm{Hf}_{2} \mathrm{~S}_{7}$ compounds are semiconductor in nature, and the $\mathrm{Ba}_{3} \mathrm{Ti}_{2} \mathrm{~S}_{7}$ compound also is metallic. Based on the obtained electronic structures, we further calculated the frequency-dependent dielectric function and other optical functions along the $\mathrm{x}$ - and z- axes.
\end{abstract}

\section{ARTICLE HISTORY}

Received 25 June 2018

Accepted 23 December 2018

\section{KEYWORDS}

Ab-initio calculations; mechanical properties; electronic properties; optical properties

\section{Introduction}

The Ruddlesden-Popper (R-P) compounds belonging to the $A_{n+1} B_{n} O_{3 n+1}(n=1,2,3$, $\infty)$ general formula consist of ' $n$ ' perovskite blocks separated into rock-salt layers and compressed between these layers. These compounds have a wide range of electrical behavior as well as from high dielectric constant paraelectric to superconductor, due to their wide forbidden energy gaps [1-5]. $A_{n+1} B_{n} \mathrm{O}_{3 n+1}$ compounds transition from cubic $(n=\infty)$ to tetragonal or orthorhombic $(n=1,2,3)$ phases when the length of the A-O and/or B-O bonds is changed. Due to its unusual physical properties, the these perovskite compounds have many application areas, such as capacitors, transistor, dielectric resonator, infrared detectors $[2,6,7]$.

Ruddlesden-Popper $\mathrm{Ba}_{3} \mathrm{X}_{2} \mathrm{~S}_{7} \quad(\mathrm{X}=\mathrm{Zr}, \mathrm{Hf}, \mathrm{Ti})$ sulfides are $\mathrm{n}=2$ members of $\mathrm{A}_{\mathrm{n}+1} \mathrm{~B}_{\mathrm{n}} \mathrm{S}_{3 \mathrm{n}+1}$ Ruddlesden-Popper sulfides. $\mathrm{Ba}_{\mathrm{n}+1} \mathrm{Zr}_{\mathrm{n}} \mathrm{S}_{3 \mathrm{n}+1}$ sulfides compounds are isostructural with $\mathrm{Sr}_{\mathrm{n}+1} \mathrm{Ti}_{\mathrm{n}} \mathrm{O}_{3 \mathrm{n}+1} \mathrm{R}-\mathrm{P}$ compounds [8]. The crystallization of the rock-salt $\mathrm{BaS}$ layers with the stacked double perovskite $\mathrm{BaZrS}_{3}$ layers forms the $\mathrm{Ba}_{3} \mathrm{Zr}_{2} \mathrm{~S}_{7}$ 
compound. As a result of the investigations, it has been found that lower $n A_{n+1} B_{n} S_{n+1}$ sulfide members have higher crystal symmetry $(\mathrm{I} 4 / \mathrm{mmm})$ whereas the higher $\mathrm{n}(2<\mathrm{n}$ $<\infty)$ members have lower crystal symmetry (Fmmm) [9]. The literature on the R-P sulfides with $\mathrm{n}=2$ members is limited. The first study on these sulfur compounds was carried out by Saeki et al. [10], and they examined the $\mathrm{Ba}_{3} \mathrm{Zr}_{2} \mathrm{~S}_{7}$ compound in orthorhombic phase using x-ray diffraction method. later, Then, Chen et al. [9] experimentally obtained the $\mathrm{Ba}_{3} \mathrm{Zr}_{2} \mathrm{~S}_{7}$ compound in the tetragonal phase. Yan et al. [11] obtained and investigated the Ruddlesden-Popper sulfides both in orthorhombic phase and tetragonal phase with a new synthetic method. Sun et al. [12] experimentally investigated the transport and thermodynamic properties of R-P compounds at different temperatures. Wang et al. [13] examined the electronic band structures and density of states of orthorhombic CZS and SZS compounds using the first principle method. As far as we know, the structural, electronic, mechanical and electronic properties of tetragonal $\mathrm{Ba}_{3} \mathrm{X}_{2} \mathrm{~S}_{7}$ compounds have not been studied up to now with the first principle method. Our aim in this work is to investigate the structural, electronic, mechanical and optical properties of the Ruddlesden-Popper $\mathrm{Ba}_{3} \mathrm{X}_{2} \mathrm{~S}_{7}(\mathrm{X}=\mathrm{Zr}$, Hf, $\mathrm{Ti})$ sulfides compounds using first principles calculations and to provide some additional information to the existing experimental works on the physical properties of these compounds.

\section{Method of calculation}

In all of our calculations that were performed using the ab-initio total-energy and molecular-dynamics program VASP (Vienna ab-initio simulation program) [14-17] that was developed within the density functional theory (DFT) [18], the exchange-correlation energy function is treated within the spin polarized GGA (generalized gradient approximation) by the density functional of Perdew et al. [19]. The potentials used for the GGA calculations take into account the $5 \mathrm{p}^{6} 6 \mathrm{~s}^{2}$ valence electrons of each Ba-, $5 \mathrm{~s}^{2} 4 \mathrm{~d}^{2}$ valence electrons of each $\mathrm{Zr}-, 4 \mathrm{f}^{14} 5 \mathrm{~d}^{2} 6 \mathrm{~s}^{2}$ valence electrons of each Hf-, $3 \mathrm{~d}^{2} 4 \mathrm{~s}^{2}$ valence electrons of each $\mathrm{Ti}$-, and $3 \mathrm{~s}^{2} 3 \mathrm{p}^{4}$ valence electrons of each $\mathrm{S}$-atoms. When including a plane-wave basis up to a kinetic-energy cutoff equal to $11.60 \mathrm{Ha}$ for $\mathrm{Ba}_{3} \mathrm{X}_{2} \mathrm{~S}_{7}$ compounds, the properties investigated in this work are well converged. The Brillouin-zone integration was performed using special $\mathrm{k}$ points sampled within the Monkhorst-Pack scheme [20]. We found that a mesh of $5 \times 5 \times 4 \mathrm{k}$ points for $\mathrm{Ba}_{3} \mathrm{Zr}_{2} \mathrm{~S}_{7}, 8 \times 8 \times 8 \mathrm{k}$ points for $\mathrm{Ba}_{3} \mathrm{Hf}_{2} \mathrm{~S}_{7}$ and $21 \times 21 \times 21 \mathrm{k}$ point for $\mathrm{Ba}_{3} \mathrm{Ti}_{2} \mathrm{~S}_{7}$ was required to describe the structural, mechanical, electronic properties. This k-point mesh guarantees a violation of charge neutrality less than $0.008 \mathrm{e}$. Such a low value is a good indicator for an adequate convergence of the calculations.

\section{Result and discussion}

The total energy is calculated to determine all the physical properties of a material. The optimization to calculate the total energy is done. The present lattice parameters have been calculated from the volume value corresponding to the minimum energy in the optimization process done using experimental atomic positions and lattice parameters [9]. The calculated lattice parameters for the tetragonal $\mathrm{Ba}_{3} \mathrm{X}_{2} \mathrm{~S}_{7}$ compounds with I4/ 
Table 1. The calculated equilibrium lattice parameters $(a, b$, and $c)$ together with the experimental values and electronic band gaps for $\mathrm{Ba}_{3} \mathrm{X}_{2} \mathrm{~S}_{7}(\mathrm{X}=\mathrm{Zr}, \mathrm{Hf}, \mathrm{Ti})$.

\begin{tabular}{lccccccr}
\hline Material & $\mathrm{a}$ & $\mathrm{b}$ & $\mathrm{c}$ & $\mathrm{E}_{0}(\mathrm{eV})$ & $\mathrm{V}_{0}\left(\AA^{3}\right)$ & $\mathrm{E}_{\mathrm{g}}(\mathrm{eV})$ & Refs. \\
\hline $\mathrm{Ba}_{3} \mathrm{Zr}_{2} \mathrm{~S}_{7}$ & 5.028 & 5.028 & 25.800 & -74.09 & 652.20 & 0.52 (I) X-G & Present \\
& 4.998 & 4.998 & 25.502 & - & 637.12 & & Exp. [9] \\
$\mathrm{Ba}_{3} \mathrm{Hf}_{2} \mathrm{~S}_{7}$ & 4.991 & 4.991 & 25.743 & -77.09 & 641.21 & 0.75 (I) X-G & \\
$\mathrm{Ba}_{3} \mathrm{Ti}_{2} \mathrm{~S}_{7}$ & 4.811 & 4.811 & 25.477 & -70.86 & 589.68 & metallic & \\
\hline
\end{tabular}

Table 2. The calculated elastic constants (in $\mathrm{GPa}$ ) for $\mathrm{Ba}_{3} \mathrm{X}_{2} \mathrm{~S}_{7}(\mathrm{X}=\mathrm{Zr}, \mathrm{Hf}, \mathrm{Ti})$.

\begin{tabular}{|c|c|c|c|c|c|c|c|}
\hline Material & Reference & $C_{11}$ & $C_{33}$ & $\mathrm{C}_{12}$ & $\mathrm{C}_{13}$ & $\mathrm{C}_{44}$ & $\mathrm{C}_{66}$ \\
\hline $\mathrm{Ba}_{3} \mathrm{Zr}_{2} \mathrm{~S}_{7}$ & Present & 124.8 & 111.4 & 28.5 & 33.1 & 26.7 & 23.3 \\
\hline $\mathrm{Ba}_{3} \mathrm{Hf}_{2} \mathrm{~S}_{7}$ & Present & 132.5 & 112.9 & 29.5 & 33.6 & 30.0 & 24.8 \\
\hline $\mathrm{Ba}_{3} \mathrm{Ti}_{2} \mathrm{~S}_{7}$ & Present & 98.5 & 91.7 & 30.1 & 28.3 & 35.1 & 25.8 \\
\hline
\end{tabular}

Table 3. The calculated isotropic bulk modulus ( $B$, in $G P a)$, shear modulus ( $G$, in $G P a)$, Young's modulus ( $E$, in $\mathrm{GPa}$ ) and Poisson's ratio for $\mathrm{Ba}_{3} \mathrm{X}_{2} \mathrm{~S}_{7}(\mathrm{X}=\mathrm{Zr}$, Hf, Ti).

\begin{tabular}{llcccccccccc}
\hline Material & Reference & $\mathrm{B}_{\mathrm{R}}$ & $\mathrm{B}_{\mathrm{V}}$ & $\mathrm{B}_{\mathrm{H}}$ & $\mathrm{G}_{\mathrm{R}}$ & $\mathrm{G}_{\mathrm{V}}$ & $\mathrm{G}_{\mathrm{H}}$ & $\mathrm{E}$ & $v$ & $\mathrm{G} / \mathrm{B}$ & $\mathrm{B} / \mathrm{G}$ \\
\hline $\mathrm{Ba}_{3} \mathrm{Zr}_{2} \mathrm{~S}_{7}$ & Present & 61.09 & 61.20 & 61.15 & 30.63 & 33.09 & 31.86 & 81.44 & 0.28 & 0.52 & 1.92 \\
$\mathrm{Ba}_{3} \mathrm{Hf}_{2} \mathrm{~S}_{7}$ & Present & 63.27 & 63.48 & 63.38 & 33.30 & 35.71 & 34.51 & 87.63 & 0.27 & 0.54 & 1.84 \\
$\mathrm{Ba}_{3} \mathrm{Ti}_{2} \mathrm{~S}_{7}$ & Present & 51.26 & 51.34 & 51.30 & 32.22 & 32.67 & 32.45 & 80.40 & 0.24 & 0.63 & 1.58 \\
\hline
\end{tabular}

mmm symmetry are given in Table 1 together with the experimental values. The obtained lattice parameter values are in agreement with the experimental values. The $\mathrm{Ba}_{3} \mathrm{X}_{2} \mathrm{~S}_{7}$ compounds from the calculated formation energy $\left(\mathrm{E}_{\mathrm{o}}\right)$ values are thermodynamically stable at the ground state.

The elastic constants, which provide an important link between the mechanical and dynamic behavior of the crystals, give important information about the nature of the forces operating on the solid. Here, the 'strain-stress' method [21] has been used to calculate the elastic constants. The 6 independent elastic constants for tetragonal compounds are calculated. The calculated elastic constants for $\mathrm{Ba}_{3} \mathrm{X}_{2} \mathrm{~S}_{7}$ compounds are given in Table 2. Unfortunately, the theoretical and experimental results to be compared with these results are not found. The elastic constants calculated for the $\mathrm{Ba}_{3} \mathrm{X}_{2} \mathrm{~S}_{7}$ compound provide the following mechanical stability criteria $[22,23]$.

$$
\begin{gathered}
C_{11}>0, \quad C_{33}>0, \quad C_{44}>0, C_{66}>0, \quad\left(C_{11}-C_{12}\right)>0, \\
\left(C_{11}+C_{33}-2 C_{13}\right)>0,\left[2\left(C_{11}+C_{12}\right)+C_{33}+4 C_{13}\right]>0
\end{gathered}
$$

The polycrystalline bulk modulus (B) and the shear modulus $(G)$ are obtained from the Voigt (V) -Reuss (R) -Hill (H) approximation [24-26] using the calculated elastic constants. The Young's modulus, Poisson's ratio, sound velocities in the environment and Debye temperature are also obtained from the calculated bulk module and shear modules. The calculated bulk modulus, shear modulus, Young's modulus and Poisson's ratio are given in Table 3. The both polycrystalline modules give a measure of hardness. The bulk module gives a resistive measure against the volume change while the shear module gives a resistive measure against shear stress. The calculated bulk and shear modulus for $\mathrm{Ba}_{3} \mathrm{Zr}_{2} \mathrm{~S}_{7}, \mathrm{Ba}_{3} \mathrm{Hf}_{2} \mathrm{~S}_{7}$, and $\mathrm{Ba}_{3} \mathrm{Ti}_{2} \mathrm{~S}_{7}$ compounds are $61.15 \mathrm{GPa}, 63.48 \mathrm{GPa}$ and $51.30 \mathrm{GPa}$, respectively. We can say that these materials are almost stiffness materials when we consider the value of Young's modulus $(81.44 \mathrm{GPa}, 87.63 \mathrm{GPa}$, and $80.40 \mathrm{GPa}$ for $\mathrm{Ba}_{3} \mathrm{Zr}_{2} \mathrm{~S}_{7}, \mathrm{Ba}_{3} \mathrm{Hf}_{2} \mathrm{~S}_{7}$, and $\mathrm{Ba}_{3} \mathrm{Ti}_{2} \mathrm{~S}_{7}$ compounds, respectively), which is a measure of 
Table 4. The calculated anisotropic factors, sound velocities $\left(v_{\mathrm{t}}, v_{1}, v_{\mathrm{m}}\right)$, the Debye temperatures for $\mathrm{Ba}_{3} \mathrm{X}_{2} \mathrm{~S}_{7}(\mathrm{X}=\mathrm{Zr}, \mathrm{Hf}, \mathrm{Ti})$.

\begin{tabular}{llcccccccc}
\hline Material & Reference & $\mathrm{A}_{1}$ & $\mathrm{~A}_{3}$ & $\mathrm{~A}_{\text {comp }}(\%)$ & $\mathrm{A}_{\text {shear }}(\%)$ & $v_{t}(\mathrm{~m} / \mathrm{s})$ & $v_{l}(\mathrm{~m} / \mathrm{s})$ & $v_{m}(\mathrm{~m} / \mathrm{s})$ & $\theta_{\mathrm{D}}(\mathrm{K})$ \\
\hline $\mathrm{Ba}_{3} \mathrm{Zr}_{2} \mathrm{~S}_{7}$ & Present & 0.63 & 0.48 & 0.089 & 3.861 & 2764 & 4985 & 3079 & 305 \\
$\mathrm{Ba}_{3} \mathrm{Hf}_{2} \mathrm{~S}_{7}$ & Present & 0.67 & 0.48 & 0.166 & 3.492 & 2590 & 4612 & 2882 & 287 \\
$\mathrm{Ba}_{3} \mathrm{Ti}_{2} \mathrm{~S}_{7}$ & Present & 0.77 & 0.75 & 0.078 & 0.693 & 2805 & 4789 & 3110 & 319 \\
\hline
\end{tabular}
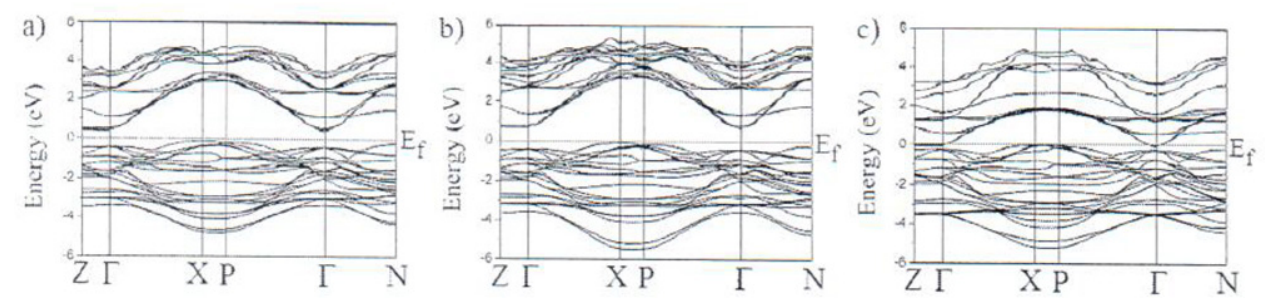

Figure 1. Energy band structure for a) $\mathrm{Ba}_{3} \mathrm{Zr}_{2} \mathrm{~S}_{7}$, b) $\mathrm{Ba}_{3} \mathrm{Hf}_{2} \mathrm{~S}_{7}$, and c) $\mathrm{Ba}_{3} \mathrm{Ti}_{2} \mathrm{~S}_{7}$.

stiffness. For all three compounds from the obtained Poisson's ratio $(v=0.25)$ and $\mathrm{G} / \mathrm{B}$ (covalent if the $\mathrm{G} / \mathrm{B} \approx 1$, ionic if the $\mathrm{G} / \mathrm{B} \approx 0.6$ ) ratio, the ionic character are dominant [27-29]. if the $B / G$ ratio is less (high) than 1.75 , a material is brittle (ductile) [30, 31]. Therefore, $\mathrm{Ba}_{3} \mathrm{Ti}_{2} \mathrm{~S}_{7}$ is brittle while $\mathrm{Ba}_{3} \mathrm{Zr}_{2} \mathrm{~S}_{7}$ and $\mathrm{Ba}_{3} \mathrm{Hf}_{2} \mathrm{~S}_{7}$ compounds are ductile (see Table 3). The Debye temperature gives important information about the physical properties of materials such as specific heat, electrical conductivity and thermal conductivity. The only acoustic modes at low temperatures are stimulated. Hence, the Debye temperature obtained from the elastic constants at the low temperature is the same as that determined from the specific temperature measurements. The calculated Debye temperatures, sound velocities [32-34] and anisotropic factors are given in Table 4. if the weight of atoms in a solid increases, the Debye temperature decreases because the sound velocity decreases in dense environments. Since the weight order of the element $\mathrm{X}$ in the Ba3X2S7 compounds changes to $\mathrm{Hf}>\mathrm{Zr}>\mathrm{Ti}$, the Debye temperature values have been obtained as $\mathrm{Ba}_{3} \mathrm{Hf}_{2} \mathrm{~S}_{7}<\mathrm{Ba}_{3} \mathrm{Zr}_{2} \mathrm{~S}_{7}<\mathrm{Ba}_{3} \mathrm{Ti}_{2} \mathrm{~S}_{7}$. The elastic anisotropies for the teragonal structure are defined as $\mathrm{A}_{1}=\mathrm{A}_{2}=4 \mathrm{C}_{44} /\left(\mathrm{C}_{11}+\mathrm{C}_{33}-2 \mathrm{C}_{13}\right)$ and $\mathrm{A}_{3}=2 \mathrm{C}_{66} /\left(\mathrm{C}_{11}\right.$ $-\mathrm{C}_{12}$ ) whereas the percentage of anisotropy in the compression and shear are defined as $A_{\text {comp }}=\left(B_{V}-B_{R}\right) /\left(B_{V}+B_{R}\right) \times 100$ and $A_{\text {shear }}=\left(G_{V}-G_{R}\right) /\left(G_{V}+G_{R}\right) \times 100$ $[35,36]$. While showing $0 \%$ value isotropy, $100 \%$ value indicates elastic anisotropy. Considering the calculated anisotropic factor values, the $\mathrm{Ba}_{3} \mathrm{X}_{2} \mathrm{~S}_{7}$ compounds exhibits very low anisotropy.

The calculated electronic band structures of the $\mathrm{Ba}_{3} \mathrm{X}_{2} \mathrm{~S}_{7}$ compounds along the high symmetry points in the $\mathrm{k}$-space and the density of states corresponding to these band structures are given in Figures 1 and 2. The $\mathrm{Ba}_{3} \mathrm{Zr}_{2} \mathrm{~S}_{7}$ and $\mathrm{Ba}_{3} \mathrm{Hf}_{2} \mathrm{~S}_{7}$ compounds have an indirect transition with $0.52 \mathrm{eV}$ and $0.75 \mathrm{eV}$ forbidden energy gap, respectively. The transitions from the maximum valence band to the minimum conduction band in both compounds occur at the $\mathrm{X}-\Gamma$ high symmetry points. These compounds are narrow semiconductors in nature. The $\mathrm{Ba}_{3} \mathrm{Ti}_{2} \mathrm{~S}_{7}$ compounds is also metallic. In the $\mathrm{Ba}_{3} \mathrm{Zr}_{2} \mathrm{~S}_{7}$ compound (see Figure 2a), the lowest valence bands are occupied by $\mathrm{Zr}$ s states. It is understood that the bands between -30 and $-25 \mathrm{eV}$ are occupied by the hybridization of $\mathrm{Ba} \mathrm{s}$ and $\mathrm{Zr} \mathrm{p}$ states (but the $\mathrm{Zr} \mathrm{p}$ states are more dominant than the $\mathrm{Ba}$ s states) 

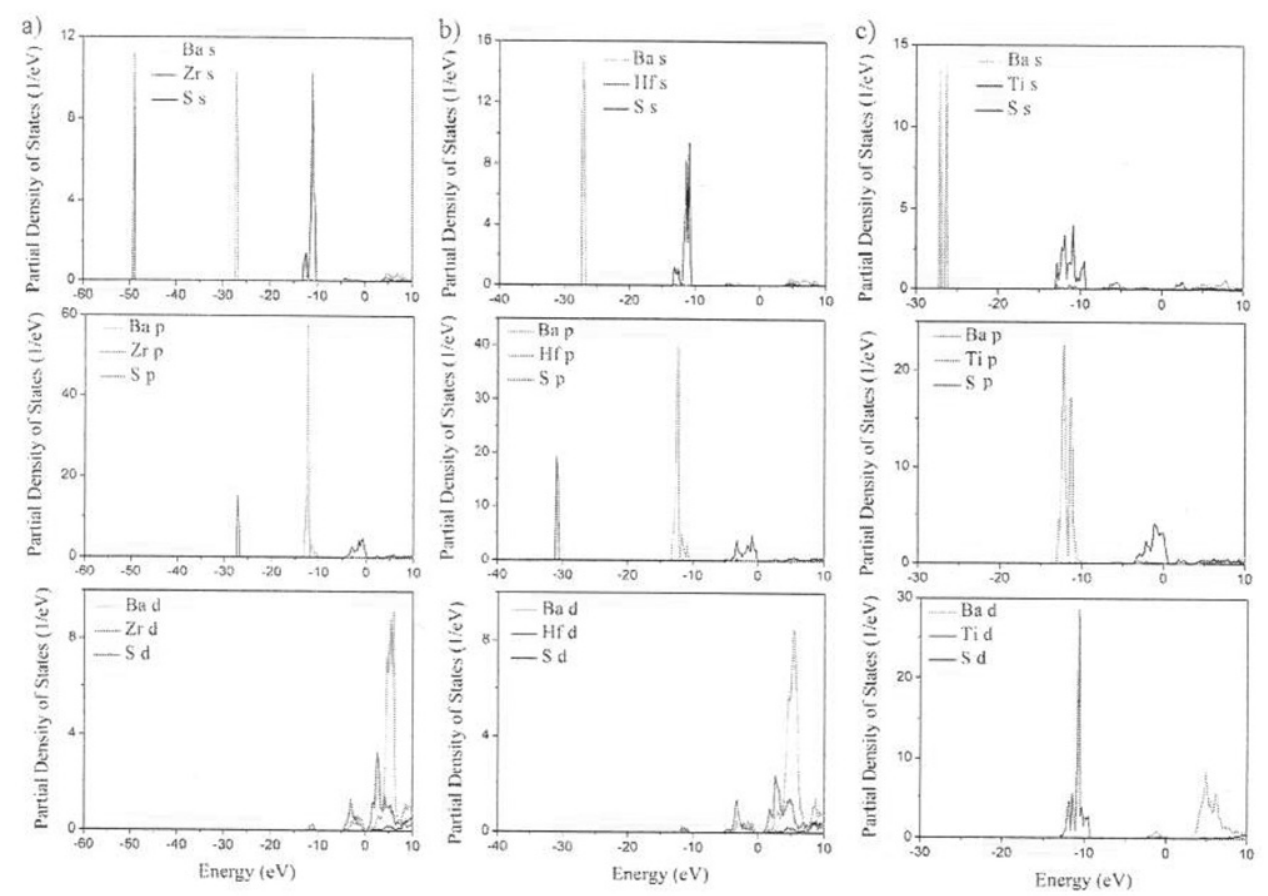

Figure 2. The projected density of states for a) $\mathrm{Ba}_{3} \mathrm{Zr}_{2} \mathrm{~S}_{7}$, b) $\mathrm{Ba}_{3} \mathrm{Hf}_{2} \mathrm{~S}_{7}$, and c) $\mathrm{Ba}_{3} \mathrm{Ti}_{2} \mathrm{~S}_{7}$.

while the bands between -15 and $-10 \mathrm{eV}$ are occupied by the hybridization of $\mathrm{S} s$ and $\mathrm{Ba} \mathrm{p}$ states (but the $\mathrm{Ba} \mathrm{p}$ states are more dominant than the $\mathrm{S} s$ states). The valence bands near the Fermi level are occupied by the hybridization of the $\mathrm{S} \mathrm{p}$ and $\mathrm{Z} \mathrm{r} \mathrm{d}+\mathrm{Ba}$ $\mathrm{d}$ states. The minimum empty conduction bands just above the Fermi level are also dominated by the $\mathrm{Zr} \mathrm{d}+\mathrm{Ba} \mathrm{d}$ states. In the $\mathrm{Ba}_{3} \mathrm{Hf}_{2} \mathrm{~S}_{7}$ compound (see Figure $2 \mathrm{~b}$ ), the lowest valence bands are occupied by Hf $\mathrm{p}$ states. The bands just above the lowest valence bands are occupied by $\mathrm{Ba}$ s states. The valence bands between -15 and $-10 \mathrm{eV}$ are occupied by the hybridization of $\mathrm{S} \mathrm{s}$ and $\mathrm{Ba} \mathrm{p}$ states, but $\mathrm{Ba} \mathrm{p}$ states dominate. It is similar to $\mathrm{Ba}_{3} \mathrm{Zr}_{2} \mathrm{~S}_{7}$ that the valence bands near the Fermi level in $\mathrm{Ba}_{3} \mathrm{Hf}_{2} \mathrm{~S}_{7}$ compound and the minimum conduction bands just above it are occupied by states. In the $\mathrm{Ba}_{3} \mathrm{Ti}_{2} \mathrm{~S}_{7}$ compounds (see Figure 2c), the lowest valence bands are occupied by $\mathrm{Ba} \mathrm{s}$ states. The valence bands between -15 and $-10 \mathrm{eV}$ are occupied by the hybridization of $\mathrm{S} s, \mathrm{Ba} \mathrm{p}$ and $\mathrm{Ti} \mathrm{d}$ states, the contribution of $\mathrm{S}$ states to these bands is very small compared to $\mathrm{Ba} \mathrm{p}$ and $\mathrm{Ti} \mathrm{d}$ states. The valence bands near the Fermi level are occupied by the $S$ p states while the minimum empty conduction bands just above the Fermi level are occupied by the $\mathrm{Ba} \mathrm{d}$ states.

The real $\left(\varepsilon_{1}\right)$ and imaginary $\left(\varepsilon_{2}\right)$ parts of the dielectric function along the $\mathrm{x}$ and $\mathrm{z}$ directions for tetragonal $\mathrm{Ba}_{3} \mathrm{X}_{2} \mathrm{~S}_{7}$ compounds using the Kramers-Kroning integral relation [37] have been calculated. Later, the energy-loss function (L), the effective number of valence electrons $\left(\mathrm{N}_{\text {eff }}\right)$ and the effective dielectric constant $\left(\varepsilon_{\text {eff }}\right)$ [29, 38-40] have been calculated using the relevant real and imaginary parts of the dielectric function. The real part of the linear dielectric function shows the physical properties of the material while the imaginer part shows the energy losses in this material. The energy 
a)

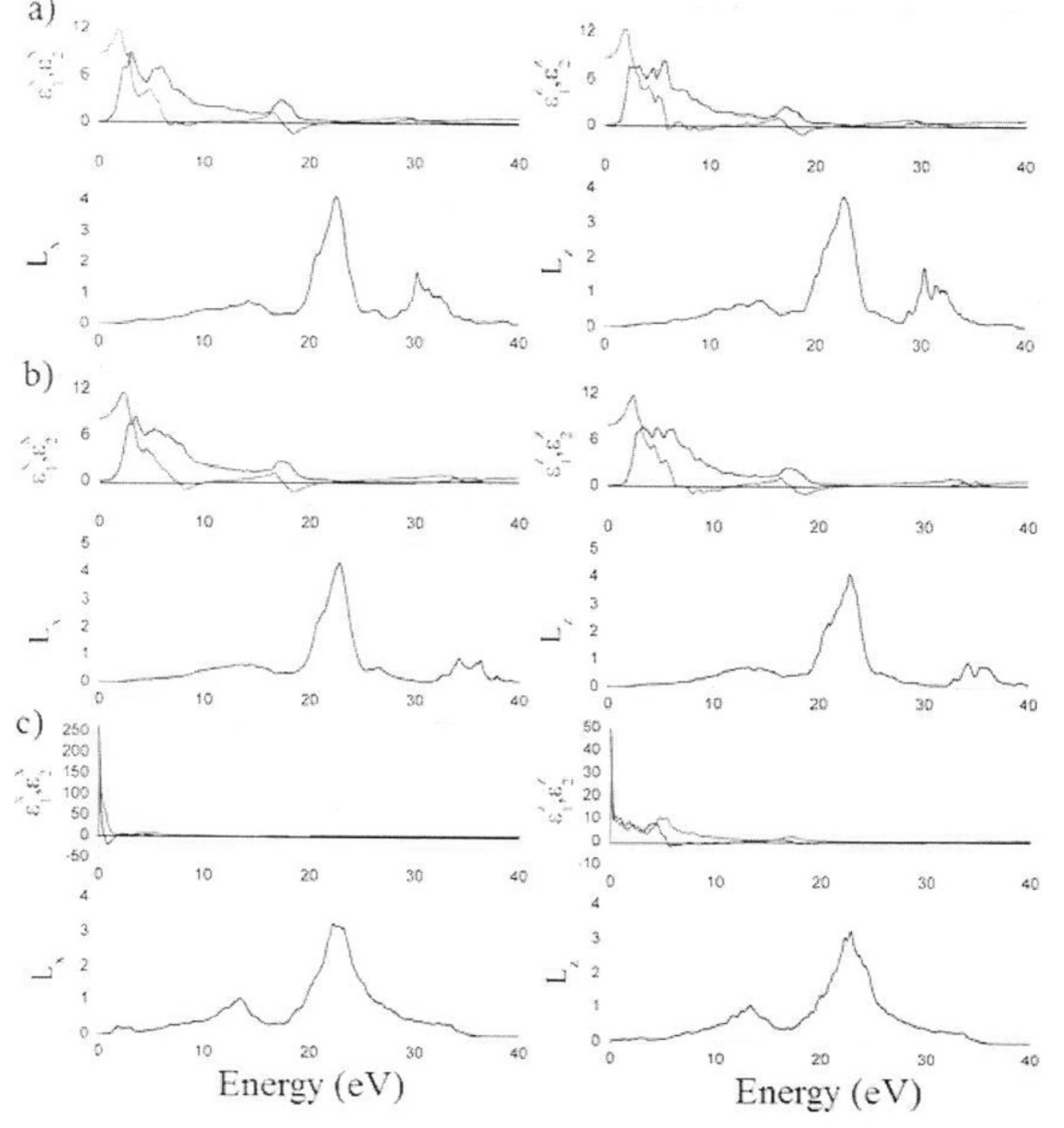

Figure 3. Energy spectra of dielectric function $\varepsilon=\varepsilon_{1}-\mathrm{i} \varepsilon_{2}$ and energy-loss function (L) along the $x$ and z- axes for a) $\mathrm{Ba}_{3} \mathrm{Zr}_{2} \mathrm{~S}_{7}$, b) $\mathrm{Ba}_{3} \mathrm{Hf}_{2} \mathrm{~S}_{7}$, and c) $\mathrm{Ba}_{3} \mathrm{Ti}_{2} \mathrm{~S}_{7}$.

loss function defines the energy loss of fast electrons traversing the material. The $\varepsilon_{2}$ in the energy range corresponding to the sharp maximums in the energy loss function is in the minimum value, and $\varepsilon_{1}$ is zero (that is, it vanishes). In Figure 3 , we have reported the real $\left(\varepsilon_{1}\right)$ and imaginary $\left(\varepsilon_{2}\right)$ parts of the linear dielectric function and the $\mathrm{L}$ energy loss functions for three compounds. when the graph of Figure 3 is examined in terms of energy, an energy region of approx. $0.8 \mathrm{eV}$ for $\mathrm{Ba}_{3} \mathrm{Zr}_{2} \mathrm{~S}_{7}$ and $\mathrm{Ba}_{3} \mathrm{Hf}_{2} \mathrm{~S}_{7}$ is transparent and has a low dispersion. This energy range corresponds to the region where the transitions between bands begin. The energy range $0.8-10 \mathrm{eV}$ for $\mathrm{Ba}_{3} \mathrm{Zr}_{2} \mathrm{~S}_{7}$ and $\mathrm{Ba}_{3} \mathrm{Hf}_{2} \mathrm{~S}_{7}$, and $0-1 \mathrm{eV}$ for $\mathrm{Ba}_{3} \mathrm{Ti}_{2} \mathrm{~S}_{7}$ indicates the energy zone in which transitions between the bands are very intense. The energy range of $20-25 \mathrm{eV}$ for the three compounds corresponds to the energy zone we gave the name of the plasmon. In this 
Table 5. Some of the principal features and singularities of the linear optical responses for $\mathrm{Ba}_{3} \mathrm{Zr}_{2} \mathrm{~S}_{7}$, $\mathrm{Ba}_{3} \mathrm{Hf}_{2} \mathrm{~S}_{7}$, and $\mathrm{Ba}_{3} \mathrm{Ti}_{2} \mathrm{~S}_{7}$.

\begin{tabular}{llllllllllll}
\hline Material & $\varepsilon_{1}(\mathrm{eV})$ & \multicolumn{3}{c}{$\mathrm{d} \varepsilon_{1} / \mathrm{dE}<0$} \\
\hline $\mathrm{Ba}_{3} \mathrm{Zr}_{2} \mathrm{~S}_{7}$ & $\varepsilon_{1}^{\mathrm{x}}$ & 6.52 & 7.50 & - & 17.48 & 7.24 & 9.65 & - & 22.07 & $\varepsilon_{2, \max }^{\mathrm{x}}$ & 3.04 \\
& $\varepsilon_{1}^{z}$ & 5.89 & 7.50 & 12.06 & 17.34 & 6.34 & 10.81 & 12.25 & 21.90 & $\varepsilon_{2, \max }^{z}$ & 5.54 \\
$\mathrm{Ba}_{3} \mathrm{Hf}_{2} \mathrm{~S}_{7}$ & $\varepsilon_{1}^{\mathrm{x}}$ & 7.58 & - & - & 17.47 & 10.70 & - & - & 22.15 & $\varepsilon_{2, \max }^{\mathrm{x}}$ & 3.52 \\
& $\varepsilon_{1}^{z}$ & 6.50 & 7.18 & - & 17.40 & 6.90 & 11.65 & - & 21.74 & $\varepsilon_{2, \max }^{z}$ & 3.25 \\
$\mathrm{Ba}_{3} \mathrm{Ti}_{2} \mathrm{~S}_{7}$ & $\varepsilon_{1}^{\mathrm{x}}$ & 0.58 & 5.57 & - & 17.32 & 1.81 & - & 12.71 & 22.12 & $\varepsilon_{2, \max }^{\mathrm{x}}$ & 0.13 \\
& $\varepsilon_{1}^{z}$ & - & 5.44 & - & 17.38 & - & - & 12.45 & 22.12 & $\varepsilon_{2, \max }^{z}$ & 0.13 \\
\hline
\end{tabular}
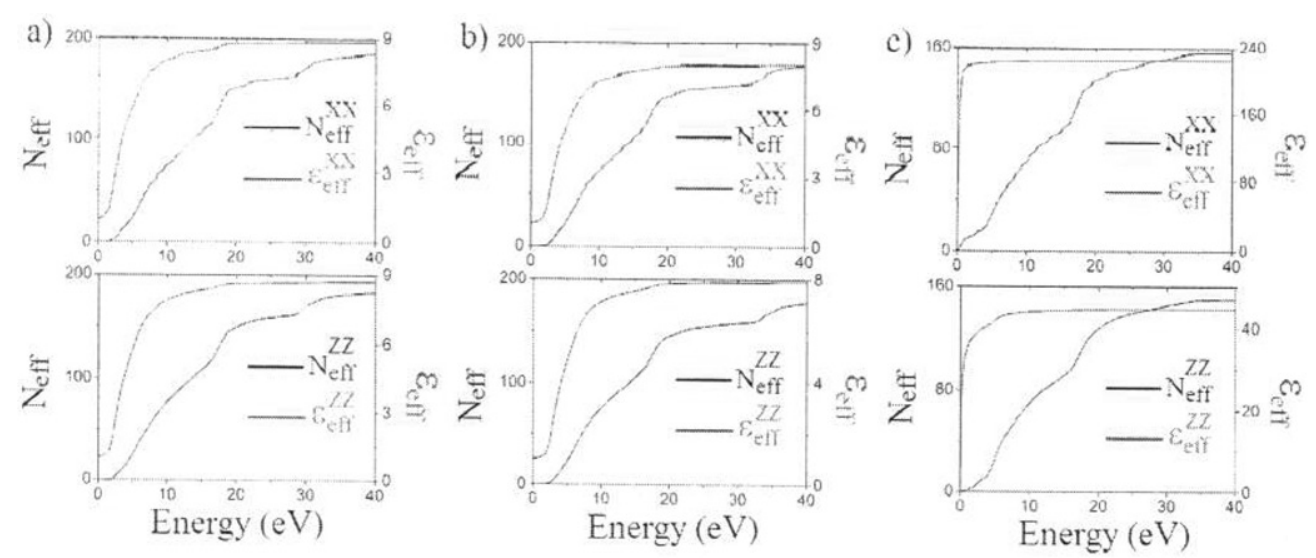

Figure 4. Energy spectra of $\mathrm{N}_{\text {eff }}$ and $\varepsilon_{\text {eff }}$ along the $\mathrm{x}$ - and z- axes for a) $\mathrm{Ba}_{3} \mathrm{Zr}_{2} \mathrm{~S}_{7}$, b) $\mathrm{Ba}_{3} \mathrm{Hf}_{2} \mathrm{~S}_{7}$, and c) $\mathrm{Ba}_{3} \mathrm{Ti}_{2} \mathrm{~S}_{7}$.

energy region, the valence electrons move together making a collective excitations. As can be seen in Figure 3, the value of $\varepsilon_{2} n$ is always positive and reaches the maximum value at the energy regions where the transitions between the bands are intense. The maximum $\varepsilon_{2}$ value obtained for all three compounds is given in Table 5 . $\varepsilon_{1}$ has also both positive and negative values. The $\mathrm{d} \varepsilon_{1} / \mathrm{dE}>0$ (from negative to positive) and $\mathrm{d} \varepsilon_{1} /$ $\mathrm{dE}<0$ (positive to negative) values of all three compounds are given in Table 5. $\varepsilon_{1}$ vanishes at these values. These values, where $\varepsilon_{1}$ is vanishes, are the points at which the reflections decrease. The energy loss function $(\mathrm{L})$ shows peaks at values where $\varepsilon_{1}$ vanishes from negative to positive. The $\mathrm{L}_{\mathrm{x}}\left(\mathrm{L}_{\mathrm{z}}\right)$ maximum values for $\mathrm{Ba}_{3} \mathrm{Zr}_{2} \mathrm{~S}_{7}, \mathrm{Ba}_{3} \mathrm{Hf}_{2} \mathrm{~S}_{7}$ and $\mathrm{Ba}_{3} \mathrm{Ti}_{2} \mathrm{~S}_{7}$ are calculated as $22.52(22.62) \mathrm{eV}, 22.76(22.96) \mathrm{eV}$ and 22.25 (22.84) eV, respectively. The calculated effective number of valence electrons $\mathrm{N}_{\text {eff }}$ and the effective dielectric constant $\varepsilon_{\text {eff }}$ are given in Figure 4. The $\varepsilon_{\text {eff }}$ constant for $\mathrm{Ba}_{3} \mathrm{Zr}_{2} \mathrm{~S}_{7}$ and $\mathrm{Ba}_{3} \mathrm{Hf}_{2} \mathrm{~S}_{7}$ reaches a saturation value at approx. $17 \mathrm{eV}$ while the $\varepsilon_{\text {eff }}$ constant for $\mathrm{Ba}_{3} \mathrm{Ti}_{2} \mathrm{~S}_{7}$ reaches a saturation value at approx. $10 \mathrm{eV}$. The $\varepsilon_{\text {eff }}$ value shows us a rapid rise that extends up to $10 \mathrm{eV}\left(\mathrm{Ba}_{3} \mathrm{Zr}_{2} \mathrm{~S}_{7}\right.$ and $\left.\mathrm{Ba}_{3} \mathrm{Hf}_{2} \mathrm{~S}_{7}\right)$ and $5 \mathrm{eV}\left(\mathrm{Ba}_{3} \mathrm{Ti}_{2} \mathrm{~S}_{7}\right)$. Then the value of $\varepsilon_{\text {eff }}$ rises more smoothly and slowly and tends to saturate at the energy $17 \mathrm{eV}$ and $5 \mathrm{eV}$. This means that the greatest contribution to $\varepsilon_{\text {eff }}$ arises from interband transitions between $0.2-17 \mathrm{eV}\left(\mathrm{Ba}_{3} \mathrm{Zr}_{2} \mathrm{~S}_{7}\right.$ and $\left.\mathrm{Ba}_{3} \mathrm{Hf}_{2} \mathrm{~S}_{7}\right)$ and $0-10 \mathrm{eV}\left(\mathrm{Ba}_{3} \mathrm{Ti}_{2} \mathrm{~S}_{7}\right)$. The $\mathrm{N}_{\text {eff }}$ reaches the saturation value at energies above $40 \mathrm{eV}$. This means that deep-lying valence orbitals participate in the interband transitions as well. 


\section{Conclusion}

We have performed the structural, mechanical, electronic, and optical properties of the Ba3Zr2S7, Ba3Hf2S7 and Ba3Ti2S7 compounds using density functional theory within the GGA approximation. The lattice parameters obtained as a result of the optimization process are in agreement with the experimental lattice parameters. The Tetragonal $\mathrm{Ba}_{3} \mathrm{X}_{2} \mathrm{~S}_{7}$ compounds with $\mathrm{I} / \mathrm{mmm}$ symmetry from the calculated formation energy $\left(\mathrm{E}_{\mathrm{o}}\right)$ values are thermodynamically stable at the ground state. For all three compounds from obtained Poisson's ratio and G/B ratio, the ionic character are dominant. We can say that these materials are almost stiffness materials when we consider the value of Young's modulus, which is a measure of stiffness. $\mathrm{Ba}_{3} \mathrm{Ti}_{2} \mathrm{~S}_{7}$ is brittle while $\mathrm{Ba}_{3} \mathrm{Zr}_{2} \mathrm{~S}_{7}$ and $\mathrm{Ba}_{3} \mathrm{Hf}_{2} \mathrm{~S}_{7}$ compounds are ductile. The Debye temperature and sound velocity for these compounds have been also calculated. Since the weight order of the element $\mathrm{X}$ in the $\mathrm{Ba}_{3} \mathrm{X}_{2} \mathrm{~S}_{7}$ compounds changes to $\mathrm{Hf}>\mathrm{Zr}>\mathrm{Ti}$, the Debye temperature values have been obtained as $\mathrm{Ba}_{3} \mathrm{Hf}_{2} \mathrm{~S}_{7}<\mathrm{Ba}_{3} \mathrm{Zr}_{2} \mathrm{~S}_{7}<\mathrm{Ba}_{3} \mathrm{Ti}_{2} \mathrm{~S}_{7}$. Considering the calculated anisotropic factor values, the $\mathrm{Ba}_{3} \mathrm{X}_{2} \mathrm{~S}_{7}$ compounds exhibits very low anisotropy. The $\mathrm{Ba}_{3} \mathrm{Zr}_{2} \mathrm{~S}_{7}$ and $\mathrm{Ba}_{3} \mathrm{Hf}_{2} \mathrm{~S}_{7}$ compounds have an indirect transition with $0.52 \mathrm{eV}$ and $0.75 \mathrm{eV}$ forbidden energy gap, respectively. The $\mathrm{Ba}_{3} \mathrm{Ti}_{2} \mathrm{~S}_{7}$ compounds is also metallic. Similar to ferroelectric oxides, there are pronounced hybridization of electronic states between $\mathrm{X}$-site cations and anions in $\mathrm{A}_{3} \mathrm{X}_{2} \mathrm{~S}_{7}$. The optical constant such as energy-loss function, the effective number of valance electrons and the effective optical dielectric constant have been calculated with the help of the real and imaginary part of dielectric function for these compounds.

\section{Funding}

This work is supported by the projects 2018-SIÜFEB-006, DPT-HAMIT and NATO-SET-193, and one of the authors (Ekmel Ozbay) also acknowledges partial support from the Turkish Academy of Sciences.

\section{References}

[1] W. Tian et al., Epitaxial growth and magnetic properties of the first five members of the layered $\mathrm{Sr} n+1 \mathrm{Ru} n \mathrm{O} 3 n+1$ oxide series, Appl. Phys. Lett. 90 (2), 022507 (2007). DOI: 10.1063/1.2430941.

[2] S. H. Butt et al., Epitaxial thin-film growth of Ruddlesden-Popper-type $\mathrm{Ba}_{3} \mathrm{Zr}_{2} \mathrm{O}_{7}$ from a $\mathrm{BaZrO}_{3}$ target by pulsed laser deposition, Appl. Phys. A. 122, 658 (2016).

[3] A. H. Reshak, Thermoelectric properties of $\mathrm{Sr}_{\mathrm{n}+} 1 \mathrm{Ti}_{\mathrm{n}} \mathrm{O}_{3 \mathrm{n}+1}(\mathrm{n}=1,2,3, \infty)$ RuddlesdenePopper Homologous Series, Renewable Energy. 76, 36 (2015). DOI: 10.1016/ j.renene.2014.11.006.

[4] K. W. Blazey, Optical absorption edge of $\mathrm{SrTiO}_{3}$ around the $105-\mathrm{K}$ phase transition, Phys. Rev. Lett. 27 (3), 146 (1971). DOI: 10.1103/PhysRevLett.27.146.

[5] J. H. Haeni et al., Epitaxial growth of the first five members of the $\operatorname{Sr}_{n+1} \operatorname{Ti}_{n} \mathrm{O}_{3 n+1}$ Ruddlesden-Popper homologous series, Appl. Phys. Lett. 78 (21), 3292 (2001). DOI: $10.1063 / 1.1371788$.

[6] J. Wu, Defect chemistry and proton conductivity in Ba-based perovskites. Ph.D. thesis, California Institute of Technology, Pasadena, CA, 2005.

[7] M. F. C. Gurgel et al., $\mathrm{BaZrO}_{3}$ photoluminescence property: an ab initio analysis of structural deformation and symmetry changes, Int. J. Quantum Chem. 111 (3), 694 (2011). DOI: $10.1002 /$ qua.22450. 
[8] Y.-C. Hung, J. C. Fettinger, and B. W. Eichhorn, $\mathrm{Ba}_{3} \mathrm{Zr}_{2} \mathrm{~S}_{7}$ the low-temperature polymorph, Acta Crystallogr. C. Cryst. Struct. Commun. C53, 827 (1997). DOI: 10.1107/ S0108270197003089.

[9] B. H. Chen, and B. Eichhorn, Structural Reinvestigation of: $\mathrm{Ba}_{3} \mathrm{Zr}_{2} \mathrm{~S}_{7}$ by single-crystal $\mathrm{x}-$ ray diffraction, Acta Crystallogr. C. Cryst. Struct. Commun. 50, 161 (1994). DOI: 10.1107/ S0108270193008972.

[10] M. Saeki, Y. Yajima, and M. Onoda, Prepararation and crystal structures of new barium zirconium sulfides, $\mathrm{Ba}_{2} \mathrm{ZrS}_{4}$ and $\mathrm{Ba}_{3} \mathrm{Zr}_{2} \mathrm{~S}_{7}$, J. Solid States Chem. 92 (2), 286 (1991). DOI: 10.1016/0022-4596(91)90336-G.

[11] J. Yan et al., Ruddlesden-Popper zirconium sulfides a novel preparation method and characterization of electronic structure, J. Solid States Chem. 229, 216 (1995). DOI: 10.1016/ 0925-8388(95)01678-3.

[12] R. R. Sun et al., The effects of elements doping on transport and thermoelectric properties of $\mathrm{Sr}_{3} \mathrm{Ti}_{2} \mathrm{O}_{7}$, J. Phys. Chem. Solids. 75 (5), 629 (2014). DOI: 10.1016/j.jpcs.2014.01.002.

[13] H. Wang, G. Gou, and J. Li, Ruddlesden-Popper perovskite sulfides $\mathrm{A}_{3} \mathrm{~B}_{2} \mathrm{~S}_{7}$ : a new family of ferroelectric photovoltaic materials for the visiblespectrum, Nano Energy. 22, 507 (2016). DOI: 10.1016/j.nanoen.2016.02.036.

[14] G. Kresse, and J. Hafner, Ab initio molecular dynamics for liquid metals, Phys. Rev. B. 47 (1), 558 (1993). DOI: 10.1103/PhysRevB.47.558.

[15] G. Kresse, and J. Furthmüller, Ab-initio total energy calculations for metals and semiconductors using a plane-wave basis set, Comput. Mater. Sci. 6 (1), 15 (1996). DOI: 10.1016/ 0927-0256(96)00008-0.

[16] G. Kresse, and D. Joubert, From ultrasoft pseudopotentials to the projector augmentedwave method, Phys. Rev. B. 59 (3), 1758 (1999). DOI: 10.1103/PhysRevB.59.1758.

[17] G. Kresse, and J. Furthmüller, Efficient iterative schemes for ab initio total- energy calculations using a plane-wave basis set, Phys. Rev. B. 54 (16), 11169 (1996). DOI: 10.1103/ PhysRevB.54.11169.

[18] P. Hohenberg, and W. Kohn, Inhomogeneous electron gas, Phys. Rev. 136, A1133 (1964).

[19] J. P. Perdew et al., Generalized gradient approximation made simple, Phys. Rev. Lett. 77 (18), 3865 (1996). DOI: 10.1103/PhysRevLett.77.3865.

[20] H. J. Monkhorst, and J. D. Pack, Special points for Brillouin-zone integrations, Phys. Rev. B. 13 (12), 5188 (1976). DOI: 10.1103/PhysRevB.13.5188.

[21] Y. Le Page, and P. Saxe, Symmetry-general least-squares extraction of elastic coefficients from ab initio total energy, Phys. Rev. B. 63, 174103 (2001).

[22] Z. J. Wu et al., Crystal structure and elastic properties of superhard $\operatorname{IrN}_{2}$ and $\operatorname{IrN}_{3}$ from first principles, Phys. Rev. B. 76, 054115 (2007).

[23] J. P. Watt, and L. Peselnick, Clarification of the Hashin-Shtrikman bounds on the effective elastic moduli of polycrystals with hexagonal, trigonal, and tetragonal symmetries, J. Appl. Phys. 51 (3), 1525 (1980). DOI: 10.1063/1.327804.

[24] W. Voight, Lehrbook der kristallphysik (Teubner, Leipsig, 1928), p. 962.

[25] A. Reuss, Berechnung der fließgrenze von mischkristallen auf grund der plastizitatsbedingung für einkristalle, $Z$ Angew. Math. Mech. 9 (1), 49 (1929). DOI: 10.1002/ zamm.19290090104.

[26] R. Hill, The elastic behavior of crystalline aggregate, Proc. Phys. Soc. A. 65 (5), 349 (1952). DOI: $10.1088 / 0370-1298 / 65 / 5 / 307$.

[27] V. V. Bannikov, I. R. Shein, and A. L. Ivanovskii, Electronic structure, chemical bonding and elastic properties of the first thorium-containing nitride perovskite $\mathrm{TaThN}_{3}$, Phys. Stat. Sol. (RRL). 3, 89 (2007). DOI: 10.1002/pssr.200600116.

[28] H. Koc, A. Yildirim, E. Tetik, and E. Deligoz, Ab initio calculation of the structural, elastik, electronic, and linear optical properties of $\mathrm{ZrPtSi}$ and TiPtSi ternary compounds, Comput. Mater. Sci. 62, 235 (2012). DOI: 10.1016/j.commatsci.2012.05.052.

[29] H. Koc, A. M. Mamedov, E. Deligoz, and H. Ozisik, First principles prediction of the elastic, electronic, and optical properties of $\mathrm{Sb}_{2} \mathrm{~S}_{3}$ and $\mathrm{Sb}_{2} \mathrm{Se}_{3}$ compounds, Solid State Sci. 14 (8), 1211 (2012). DOI: 10.1016/j.solidstatesciences.2012.06.003. 
[30] I. R. Shein, and A. L. Ivanovskii, Elastic properties of mono- and polycrystalline hexagonal $\mathrm{AlB}_{2}$-like diborides of $\mathrm{s}, \mathrm{p}$ and $\mathrm{d}$ metals from first-principles calculations, J. Phys.: Condens. Matter. 20 (41), 415218 (2008). DOI: 10.1088/0953-8984/20/41/415218.

[31] F. Pogh, Relations between the elastic moduli and the plastic properties of polycrystalline pure metals, Philos. Mag. 45, 823 (1954).

[32] I. Johnston, G. Keeler, R. Rollins, and S. Spicklemire, Solids State Physics Simulations: The Consortium for Upper Level Physics Software (Wiley, New York, NY, 1996).

[33] O. L. Anderson, A simplified method for calculating the Debye temperature from elastic constants, J. Phys. Chem. Solids. 24 (7), 909 (1963). DOI: 10.1016/0022-3697(63)90067-2.

[34] E. Schreiber, O. L. Anderson, and N. Soga, Elastic Constants and Their Measurements (McGraw-Hill, New York, NY, 1973).

[35] H. Zhai, X. Li, and J. Du, First-principles calculations on elasticity and anisotropy of tetragonal tungsten dinitride under pressure, Mater. Trans. 53 (7), 1247 (2012). DOI: 10.2320/matertrans.M2011373.

[36] D. H. Chung, and W. R. Buessem, In: F. W. Vahldiek, and S. A. Mersol, editors. Anisotropy in Single Crystal Refractory Compounds (Plenum, New York, NY, 1968), p. 217.

[37] H. R. Philipp, and H. Ehrenreich, Optical properties of semiconductors, Phys. Rev. 129 (4), 1550 (1963). DOI: 10.1103/PhysRev.129.1550.

[38] H. Koc et al., Mechanical, electronic, and optical properties of $\mathrm{Bi}_{2} \mathrm{~S}_{3}$ and $\mathrm{Bi}_{2} \mathrm{Se}_{3}$ compounds: first principle investigations, J. Mol. Model. 20, 1 (2014).

[39] L. Marton, Experiments on low-energy electron scattering and energy losess, Rev. Mod. Phys. 28 (3), 172 (1956). DOI: 10.1103/RevModPhys.28.172.

[40] O. V. Kovalev, Representations of the Crystallographic Space groups. Irreducible Representations Induced Representations and Corepresentations (Gordon and Breach, Amsterdam, 1965). 